\title{
Enseñanza de las ciencias y problemas relevantes de la ciudadanía. Transferencia al aula
}

\author{
Vito Battista Brero Peinado \\ Departamento de Didáctica de la Matemática, de las Ciencias Sociales y de las Ciencias \\ Experimentales. Universidad de Málaga. España. vbrero@uma.es \\ ORCID: https://orcid.org/0000-0003-0881-1839
}

Science education and relevant citizenship issues. Transfer to the classroom

Para citar la obra reseñada: Brero Peinado, V. B. (2021). Reseña de Cebrián, D., Franco, A. J., Lupión, T., Acebal, M. C. y Blanco, A. (Coordinadores) (2021). Enseñanza de las ciencias y problemas relevantes de la ciudadanía. Transferencia al aula. Barcelona: Editorial Graò, 394 págs. Volumen 23, "Colección Análisis y Estudios" de la "Serie Investigación educativa/Educación para la ciudadanía” (1a edición: enero 2021. ISBN: 978-84-18058-95-0). Revista de Educación Ambiental y Sostenibilidad 3(1), 1401. doi: 10.25267/Rev_educ_ambient_sostenibilidad.2021.v3.i1.1401

Esta obra recoge trabajos del grupo de investigación "Enseñanza de las ciencias y competencias" (ENCIC) (HUM-974) (encic.es) de la Universidad de Málaga derivados fundamentalmente de su proyecto actual de I+D "Desarrollo de competencias en problemas de la vida diaria mediante prácticas científicas de argumentación, indagación y modelización en enseñanza secundaria y universitaria" (CPAIM) (EDU2017-82197-P).

De acuerdo con los planteamientos más innovadores de la educación científica actual se presenta un conjunto numeroso e importante de propuestas de intervención educativa a partir de situaciones cotidianas, personal y socialmente relevantes, relacionadas con el mundo las ciencias experimentales. Se utilizan expresa e intencionadamente estas situaciones para el desarrollo de la competencia científica en sus múltiples perspectivas: identificación y comprensión de los problemas, búsqueda y análisis de información, indagación, argumentación, razonamiento, modelización, reflexión, pensamiento crítico, toma de decisiones, posicionamiento y compromiso personal, implicación y activismo colectivo, habilidades comunicativas... Todo ello con la finalidad de contribuir a la formación necesaria e imprescindible que posibilite una participación ciudadana responsable en las frecuentes controversias sociales contemporáneas y futuras.

Se compone la obra de cuatro bloques que dan una visión completa de los diferentes perfiles a los que se dirige: a estudiantes de educación infantil, primaria, secundaria, bachillerato y universitaria, así como a profesorado en formación inicial y profesorado activo en formación permanente. Además, ofrece una abundante, variada e importante bibliografía.

Los dos primeros bloques recogen propuestas educativas con estudiantes de varios niveles educativos. El primero, y más abundante, con estudiantes de educación secundaria y bachillerato, mayoritariamente basadas en secuencias de enseñanza aprendizaje (SEA) en las que prima el desarrollo de la argumentación e indagación, así como la modelización, toma de decisiones y el juego de rol en algunas de ellas. Las numerosas y variadas temáticas tratadas se encuadran en disciplinas tradicionales 
como la Educación Ambiental, Educación para la Salud, la Nutrición y el Consumo. En el segundo bloque, con estudiantes universitarios de los grados de ciencias e ingeniería se proponen en ambos casos secuencias de actividades. En el primer caso, la secuencia de enseñanza-aprendizaje (SEA) se diseña como contrapunto al modelo tradicional de prácticas en ciencias experimentales. En el segundo caso la secuencia de actividades se dirige al desarrollo de la argumentación como competencia general, tanto en su vertiente comunicativa como en la de elaboración y evaluación, así como en la de contraargumentación en el ámbito profesional de la ingeniería.

El tercer bloque presenta numerosas y variadas propuestas educativas con profesorado en formación inicial de educación infantil, primaria, secundaria y bachillerato. Desde trabajar la argumentación en una feria de ciencias, la prevención de la enfermedad cardiovascular o la controversia sobre la lactancia con futuros docentes en educación infantil; la discriminación argumentada de la información o la publicidad sobre el uso y el consumo relacionados con la nutrición, tecnología, energía, salud; hasta el activismo personal y colectivo ante problemas sociales relevantes en los otros niveles educativos.

El último bloque culmina con dos experiencias innovadoras dirigidas a la formación permanente de profesorado de ciencias en activo. Una indaga y analiza las creencias y percepciones sobre la enseñanza y el aprendizaje de las ciencias de profesorado en activo como condicionantes internos, así como otros condicionantes externos al profesorado, como el entorno profesional y educativo, potencialmente influyentes en su ejercicio de enseñanza. Otra desarrolla una experiencia formativa basada en dos proyectos de intervención en ciencias experimentales mediante la aplicación de prácticas científicas de indagación y contextualización siguiendo la metodología STEAM en centros educativos públicos no universitarios de Málaga.

En conclusión, por su variedad y relevancia temática, su enfoque metodológico innovador y actual, así como por la incidencia que puede tener en los distintos actores de la comunidad educativa, este libro puede resultar de gran valor para ilustrar y orientar la enseñanza y aprendizaje de las ciencias. 